01.1;08.3;09.4

\title{
Оптические и тепловые свойства гибридного металлодиэлектрического отражателя
}

\author{
() Е.А. Харитонова ${ }^{1}$, Е.И. Гиршова ${ }^{2,3}$, А.В. Белоновский ${ }^{2,3}$, К.М. Морозов ${ }^{2,3}$, К.А. Иванов ${ }^{3}$, О.И. Симчук ${ }^{2}$ \\ ${ }^{1}$ Санкт-Петербургский политехнический университет Петра Великого, Санкт-Петербург, Россия \\ ${ }^{2}$ Санкт-Петербургский национальный исследовательский Академический университет им. Ж.И. Алфёрова РАН, \\ Санкт-Петербург, Россия \\ ${ }^{3}$ Университет ИТМО, Санкт-Петербург, Россия \\ E-mail: elenakharr@mail.ru
}

Поступило в Редакцию 15 июля 2020г.

В окончательной редакции 28 сентября 2020 г.

Принято к публикации 28 сентября 2020 г.

Рассмотрены тепловые и оптические свойства комбинированного отражателя, состоящего из слоя золота и распределенного брэгговского отражателя, составленного из чередующихся слоев $\operatorname{In}_{0.52} \mathrm{Al}_{0.48} \mathrm{As}_{2} / \mathrm{In}_{0.53} \mathrm{Ga}_{0.47} \mathrm{As}$. Показано, что можно достичь высокого коэффициента отражения при низком поглощении в металле и относительно малой суммарной толщине диэлектрического отражателя.

Ключевые слова: вертикально-излучающий лазер, распределенный брэгговский отражатель, металлодиэлектрический отражатель, арсенид индия-алюминия, арсенид индия-галлия.

DOI: 10.21883/PJTF.2021.02.50538.18468

Вертикально-излучающие лазеры (ВИЛ) применяются в первую очередь для высокоскоростной передачи данных. Такие лазеры характеризуются малой угловой расходимостью, симметричной диаграммой направленности выходного оптического излучения. Высокая температурная и радиационная стабильность обеспечивают широкую область применения вертикально-излучающих лазеров. Групповая технология изготовления и возможность тестирования приборов непосредственно на пластине являются важным преимуществом со стороны организации производства ВИЛ [1,2]. Непрерывное развитие рынка информационных технологий требует постоянного увеличения скорости передачи данных и удешевления процесса изготовления лазера [3-5]. Для работы ВИЛ требуется высокоэффективный отражатель, настроенный на рабочую длину волны лазера, обусловленную окнами прозрачности оптического волокна: 850 , 1300 и $1550 \mathrm{~nm}$. На данный момент в качестве таких рефлекторов используются классические распределенные брэгговские отражатели (РБО) [6,7]. Подобные слоистые структуры выращиваются на полупроводниковой подложке методом молекулярно-пучковой эпитаксии, это высокотехнологичный, длительный и дорогостоящий процесс. Скорость роста при эпитаксиальных процессах составляет порядка одного монослоя (толщиной порядка $0.5 \mathrm{~nm}$ ) в секунду, и время роста структуры составляет десятки часов. Уменьшение суммарной толщины диэлектрического зеркала позволило бы ускорить и удешевить процедуру изготовления ВИЛ [8]. В качестве альтернативы использования РБО возможно применение комбинированного металлодиэлектрического отражателя, состоящего из РБО и металлического слоя. Комбинированные оптические элементы находят применение во многих современных оптических устройствах в качестве оптимального решения различных проблем, связанных с оптимизацией работы прибора или его производства $[9,10]$. Металлические зеркала не принято использовать в конструкциях лазеров из-за существенного поглощения излучения и возникающего вследствие этого нагрева, ведущего к деформациям структуры. Однако, если покрыть металлическое зеркало со стороны падения света несколькими парами слоев РБО, поглощение будет существенно уменьшено, а нагрев и потери перестанут быть критическими $[11,12]$. Например, если металл на рабочей длине волны поглощает $1 \%$ излучения, то слой металла, закрытый РБО, отражающим 95\%, будет поглощать $1 \%$ от 5\%, т.е. 0.0005 излучения [11]. Известно, что с ростом числа слоев РБО коэффициент отражения увеличивается все медленнее и медленнее (если РБО из 20 слоев имеет коэффициент отражения $90 \%$, то для достижения 99\% отражения потребуется уже около 40 слоев); таким образом, незначительное понижение требуемого коэффициента отражения приводит к серьезному уменьшению толщины структуры. Тем не менее при использовании металлического слоя необходимо иметь в виду, что в случае нагрева и температурного расширения слоев диэлектрического отражателя, прилегающих к металлу, может измениться его коэффициент отражения на рабочей длине волны [13], поэтому необходимо моделировать не только оптические параметры системы, но и ее термодинамику. Цель настоящей работы - исследовать возможности уменьшения эпитаксиальной структуры, используемой в вертикально-излучающем лазере, путем применения комбинированного зеркала, содержащего металлический слой.

В качестве материалов для диэлектрической части комбинированного отражателя могут использоваться ар- 


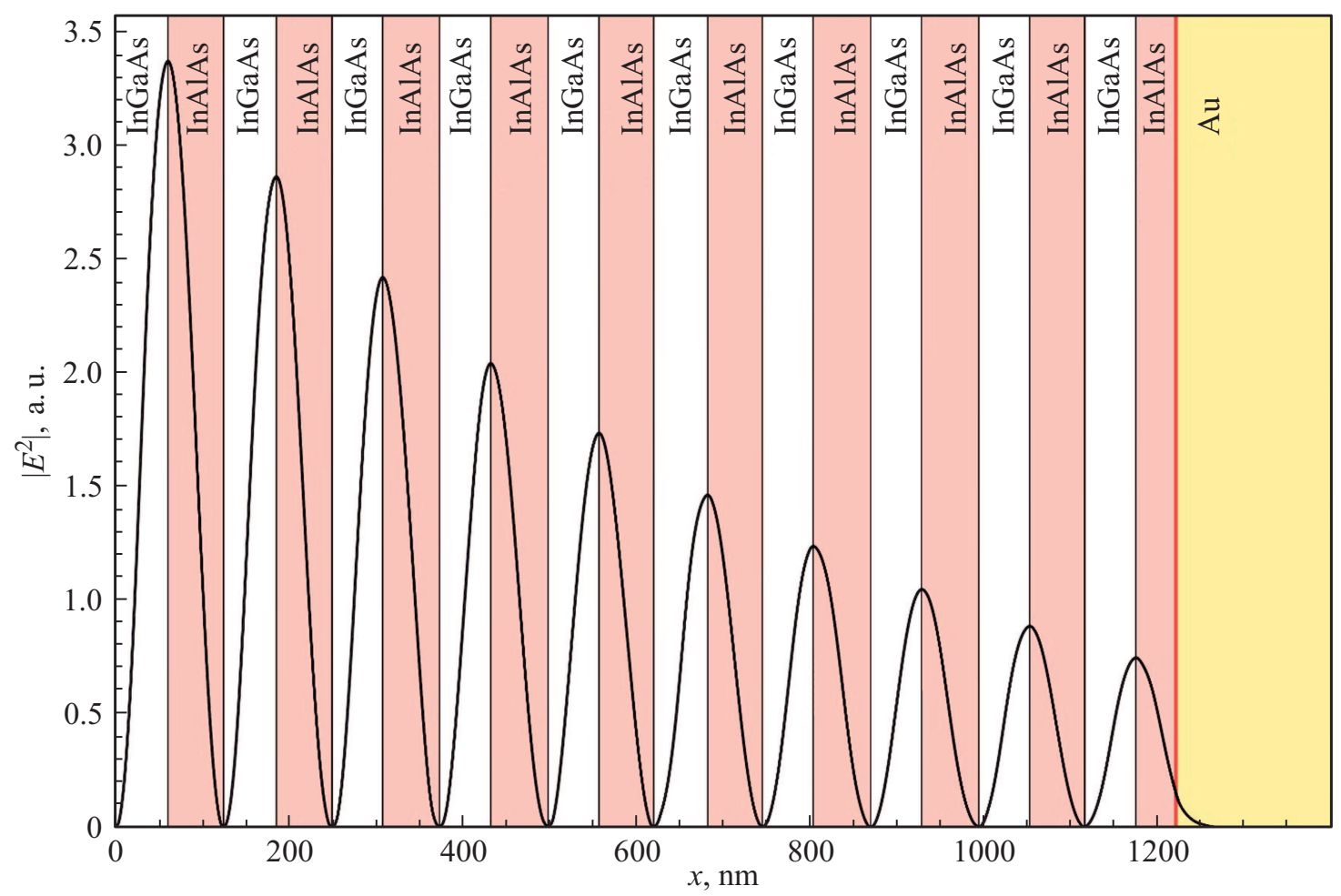

Рис. 1. Профиль поля электромагнитной волны в структуре комбинированного отражателя.

сенид индия-алюминия $\left(\operatorname{In}_{0.52} \mathrm{Al}_{0.48} \mathrm{As}\right)$ и арсенид индиягаллия $\left(\mathrm{In}_{0.53} \mathrm{Ga}_{0.47} \mathrm{As}\right)$. Эти соединения решеточносогласованы с подложкой из фосфида индия, но не обладают высоким оптическим контрастом на рабочих длинах волн, поэтому для достижения высокого коэффициента отражения распределенного брэгговского отражателя необходимо большое число слоев, что, как уже было указано, ведет к увеличению стоимости конечного устройства. В качестве металла было взято золото, поскольку оно широко используется в создании лазерных структур в качестве контактов и других элементов, а также обладает на выбранной длине волны высоким коэффициентом отражения света. Пример структуры комбинированного отражателя приведен на рис. 1 .

Методом матриц переноса был проведен расчет спектров отражения и поглощения для РБО из выбранных материалов, а также для комбинированного отражателя, состоящего из слоя металла, покрытого сверху несколькими слоями РБО. На рис. 1 приведен профиль квадрата электрического поля в структуре при воздействии светового луча с длиной волны $850 \mathrm{~nm}$. Было показано, что поглощение в металле существенно снижается по сравнению с поглощением в случае простого металлического зеркала (рис. 2, a), а комбинированный отражатель требует меньшей суммарной толщины диэлектрической части, чем классический РБО (рис. 2,b),

Поскольку нагрев металла и прилегающей к нему части брэгговского отражателя может повлечь изменение оптических характеристик системы, было проведено теоретическое исследование свойств структуры комбинированного отражателя, состоящего из десяти пар слоев арсенида индия-алюминия $\left(\operatorname{In}_{0.52} \mathrm{Al}_{0.48} \mathrm{As}\right)$ и арсенида индия-галлия $\left(\operatorname{In}_{0.53} \mathrm{Ga}_{0.47} \mathrm{As}\right)$, настроенных на длину волны $850 \mathrm{~nm}$, покрывающих слой золота. Поглощение света в металле порождает в нем тепловыделение, плотность которого можно выразить следующим выражением:

$$
F(x, t)=\frac{A(\lambda) I(t) \alpha(x, \lambda)|E(x)|^{2}}{\int \alpha(x)|E(x)|^{2} d x},
$$

где $I(t, \lambda)$ - интенсивность падающего луча, $\alpha(x, \lambda)-$ коэффициент поглощения на соответствующей длине волны $\lambda$. Пространственное распределение температуры системы во времени меняется в соответствии с уравнениями

$$
\begin{gathered}
c \rho \frac{d T}{d t}=\frac{d}{d x}\left(\kappa \frac{d T}{d x}\right)+F(x, t), \\
\frac{d T}{d t}=D \frac{d^{2} T}{d x^{2}}
\end{gathered}
$$

где $c$ и $\rho$ - теплоемкость и плотность материала, $\kappa-$ его теплопроводность, а $D=\kappa /(c \rho)$ - температуропроводность. Для конкретной структуры уравнения могут быть решены численно методом конечных элементов. Для определения тепловых свойств структуры полезно определить характерные времена релаксации неоднородности распределения температуры [14,15], для этого было проведено моделирование временно́й эволюции профиля распределения температуры при нагревании 

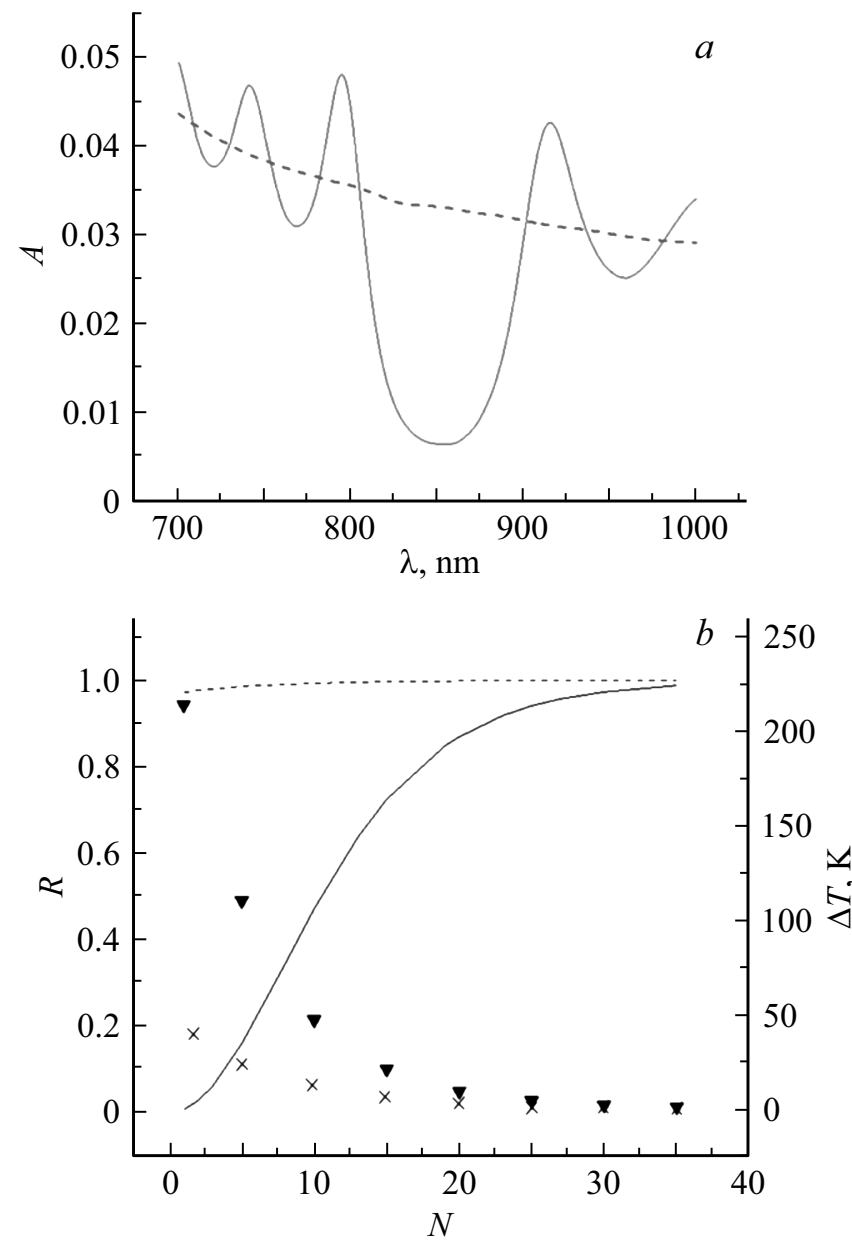

Pис. 2. $a-$ спектры поглощения одинарного слоя золота (штриховая линия) и комбинированного отражателя, в котором слой золота покрыт десятью парами РБО (сплошная линия). $b$ - зависимость коэффициента отражения на рабочей длине волны $(R)$ от количества пар слоев РБО для комбинированного отражателя со слоем золота (штриховая линия) и для РБО без металла (сплошная линия). Треугольниками показаны значения максимальной температуры в слое золота при нагреве структуры с соответствующим количеством слоев единичным импульсом с плотностью энергии $10 \mathrm{~mJ} / \mathrm{cm}^{2}$, крестиками - максимальный нагрев структуры при облучении с плотностью мощности $5 \cdot 10^{4} \mathrm{~W} / \mathrm{cm}^{2}$.

структуры бесконечно коротким импульсом лазерного излучения.

На рис. 3, а представлена эволюция пространственного распределения температуры в структуре, изображенной на рис. 1, при облучении ее бесконечно коротким импульсом с плотностью энергии $10 \mathrm{~mJ} / \mathrm{cm}^{2}$, что соответствует плотности энергии одного импульса при средней мощности $5 \mathrm{~mW}$, диаметре апертуры $3 \mu \mathrm{m}$ и частоте модуляции $5 \mathrm{MHz}$ [14]. Можно видеть, что в рассматриваемой структуре релаксация температуры происходит достаточно быстро (за время порядка $0.1 \mathrm{~ns}$ ), что соответствует частоте модуляции $10 \mathrm{GHz}$. Так как слои РБО, расположенные в непосредственной близости от слоя металла, в котором идет активное тепловыделение, претерпевают температурное расширение, необходим контроль отражательной способности комбинированного отражателя в момент максимального повышения температуры диэлектрической части. Коэффициент температурного расширения для $\mathrm{In}_{0.52} \mathrm{Al}_{0.48} \mathrm{As}$ составляет порядка $6 \cdot 10^{-6} \mathrm{~K}^{-1}$, а для $\mathrm{In}_{0.53} \mathrm{Ga}_{0.47} \mathrm{As}$ - порядка $4 \cdot 10^{-6} \mathrm{~K}^{-1}$. Таким образом, при повышении температуры на $50 \mathrm{~K}$, что можно считать оценкой сверху степени нагрева диэлектрической части комбинированного отражателя с десятью слоями РБО, под воздействием единичного бесконечно короткого лазерного импульса с плотностью энергии $10 \mathrm{~mJ} / \mathrm{cm}^{2}$ толщина слоя может увеличиться на $0.072 \%$. Для отражателя из выбранных материалов, настроенных на длину волны $850 \mathrm{~nm}$, изменение толщины прилегающего к металлу слоя будет составлять менее $0.04 \mathrm{~nm}$. Такое незначительное изменение геометрии системы не может значимо повлиять
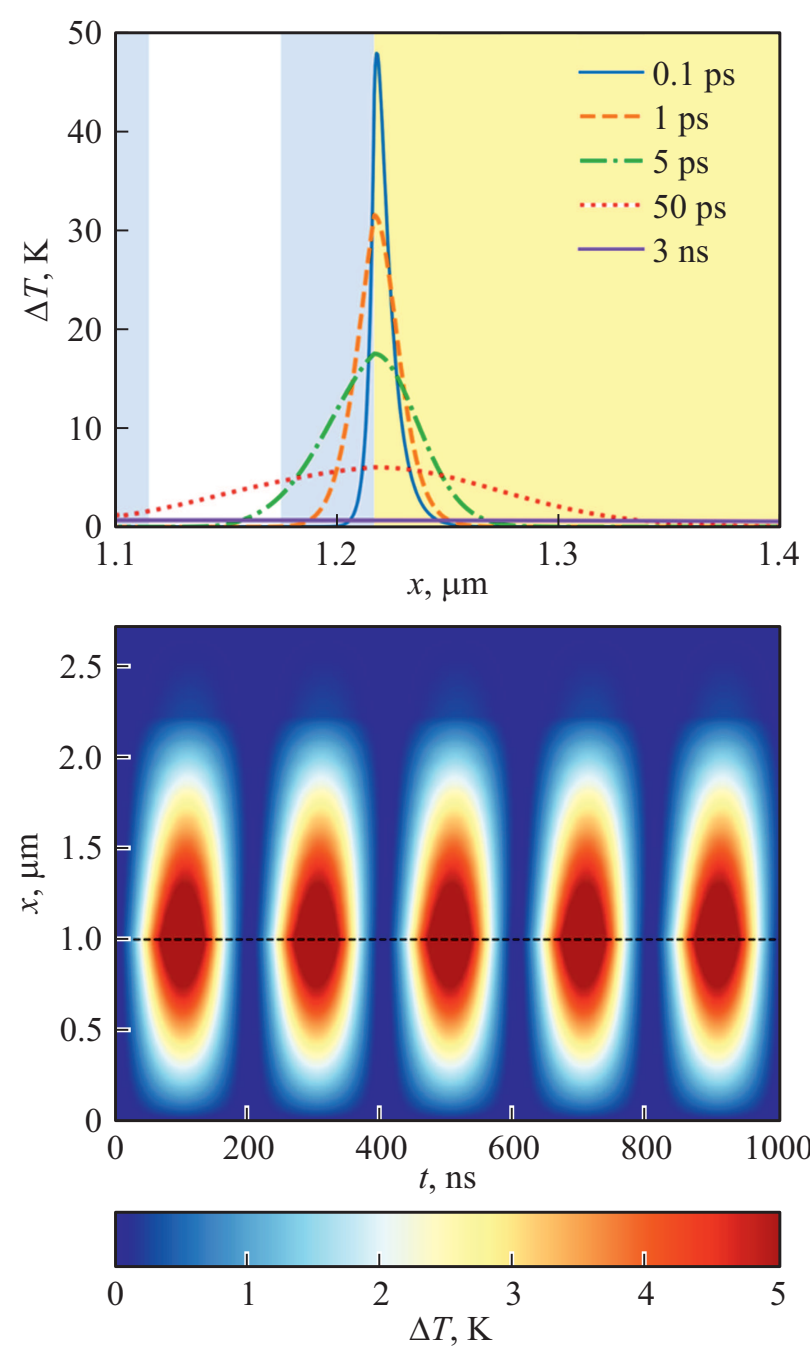

Рис. 3. $a-$ модификация пространственного профиля температуры в структуре после нагрева одним лазерным импульсом с плотностью энергии $10 \mathrm{~mJ} / \mathrm{cm}^{2} . b-$ временно́е и пространственное распределение температуры при периодическом нагреве структуры лазером с частотой модуляции $5 \mathrm{MHz}$. 
на ее спектр отражения и не нарушит механическую целостность системы.

На рис. 3, $b$ показано временно́е и пространственное распределение температуры при периодическом нагреве структуры лазером с частотой модуляции $5 \mathrm{MHz}$ при средней плотности мощности $5 \cdot 10^{4} \mathrm{~W} / \mathrm{cm}^{2}$ (что соответствует средней мощности лазера $5 \mathrm{~mW}$ и диаметру апертуры $3 \mu \mathrm{m}[14])$. Можно видеть, что при выбранных параметрах излучения нагрев структуры, обусловленный поглощением света в металле, не превышает $5 \mathrm{~K}$, при облучении немодулированным излучением с такой же плотностью мощности не будет превышать $2.5 \mathrm{~K}$.

При уменьшении толщины РБО нагрев структуры, обусловленный поглощением света в структуре, будет увеличиваться. Рис. 2, $b$ показывает, что максимальная температура, достигаемая в слое золота под воздействием лазерного импульса, падает с ростом количества слоев диэлектрического отражателя. При отсутствии РБО максимальная температура нагрева золота мгновенным импульсом составляет более $200 \mathrm{~K}$, а при стационарном облучении с плотностью мощности $5 \cdot 10^{4} \mathrm{~W} / \mathrm{cm}^{2}$ нагрев структуры составит около $20 \mathrm{~K}$.

Таким образом, использование в конструкции ВИЛ гибридного металлодиэлектрического отражателя позволит существенно уменьшить суммарную толщину структуры, выращиваемой методом молекулярно-пучковой эпитаксии, и упростить процесс изготовления диэлектрической части без угрозы деструктивных изменений из-за поглощения и нагрева в металле.

\section{Финансирование работы}

Работа выполнена в рамках государственного задания по теме 0791-2020-0002 FSRM-2020-0002 „Создание и исследование новых типов светоизлучающих приборов и структур на основе одномерных и трехмерных микрорезонаторов с квантово-размерной активной областью“ и поддержана грантом Российского научного фонда (проект № 16-12-10503).

\section{Конфликт интересов}

Авторы заявляют, что у них нет конфликта интересов.

\section{Список литературы}

[1] C. Wilmsen, L. Coldren, H. Temkin, Vertical-cavity surfaceemitting lasers: design, fabrication, characterization, and applications (Cambridge University Press, 2001).

[2] J.L. Jewell, J.P. Harbison, A. Scherer, Y.H. Lee, L.T. Florez, IEEE J. Quant. Electron., 27, 1332 (1991). DOI: $10.1109 / 3.8950$

[3] A. Liu, P. Wolf, J. Lott, D. Bimberg, Photon. Res., 7, 121 (2019).

[4] A.A. Juarez, X. Chen, K. Li, J. Himmelreich, J.E. Hurley, S.K. Mishra, C. Fiebig, G. Larisch, D. Bimberg, M.-J. Li, in 2020 Optical Fiber Communications Conf. and Exhibition (San Diego, 2020), p. W4D.2.

https://doi.org/10.1364/OFC.2020.W4D.2
[5] F. Koyama, J. Lightwave Technol., 24, 4502 (2006).

[6] K. Streubel, S. Rapp, J. Andre, J. Wallin, IEEE Photon. Technol. Lett., 8, 1121 (1996).

[7] D. Takahashi, S. Lee, M. Shirao, T. Shindo, K. Shinno, T. Amemiya, N. Nishiyama, S. Arai, IEEE J. Quant. Electron., 48, 688 (2012). DOI: 10.1109/JQE.2012.2190822

[8] J.-L. Leclercq, P. Regreny, P. Viktorovitch, A. Bakouboula, T. Benyattou, I. Sagnes, G. Saint-Girons, C. Meriadec, A. Mereuta, S. Bouchoule, A. Plais, J. Jacquet, SPIE Proc., 4755, 448 (2002).

[9] A.J. Gallant, M.A. Kaliteevski, D. Wood, M. Petty, R.A. Abram, S. Brand, G.P. Swift, D. Zeze, J.M. Chamberlain, Appl. Phys. Lett., 91, 161115 (2007). DOI: $10.1063 / 1.2800381$

[10] D. Liu, L. Chen, D. Cao, F. Liu, Opt. Commun., 475, 126197 (2020). DOI:10.1016/j.optcom.2020.126197

[11] K. Mehta, T. Detchprohm, Y.J. Park, Y.-S. Liu, O. Moreno, S.R. Alugubelli, S. Wang, F.A. Ponce, S.-C. Shen, R.D. Dupuis, P.D. Yoder, IEEE J. Quant. Electron., 53, 1 (2017). DOI: $10.1109 / \mathrm{JQE} .2017 .2766288$

[12] B. Zhang, T. Okimoto, T. Tanemura, Y. Nakano, Jpn. J. Appl. Phys. 53, 112703 (2014).

[13] P.C. Won, Y. Lai, W. Zhang, L. Jinsong, J.A.R. Williams, Opt. Commun., 265, 494 (2006). DOI: $10.1016 /$ j.optcom.2006.04.024

[14] С.А. Блохин, Н.А. Малеев, А.Г. Кузьменков, Ю.М. Шерняков, И.И. Новиков, Н.Ю. Гордеев, В.В. Дюделев, Г.С. Соколовский, В.И. Кучинский, М.М. Кулагина, М.В. Максимов, В.М. Устинов, А.Р. Ковш, С.С. Михрин, Н.Н. Леденцов, ФТП, 40 (5), 633 (2006).

[15] E.I.Girshova, A.P. Mikitchuk, A.V. Belonovski, K.M. Morozov, K.A. Ivanov, G. Pozina, K.V. Kozadaev, A.Yu. Egorov, M.A. Kaliteevski, Opt. Express, 28, 26161 (2020). 